\title{
Lung cancer with concurrent EGFR mutation and ROSI rearrangement: a case report and review of the literature
}

\section{You-cai Zhu',2,* \\ Chun-wei $\mathrm{Xu}^{3, *}$ \\ Xiao-qian $\mathrm{Ye}^{4}$ \\ Man-xiang Yin ${ }^{4}$ \\ Jin-xian Zhang ${ }^{2}$ \\ Kai-qi Du \\ Zhi-hao Zhang ${ }^{2}$ \\ Jian $\mathrm{Hu}^{\prime}$}

'Department of Thoracic Surgery,

The First Affiliated Hospital of

Medical School of Zhejiang University,

Hangzhou, ${ }^{2}$ Department of Thoracic

Surgery, Chinese People's Armed

Police Force, Zhejiang Corps Hospital,

Jiaxing, Zhejiang, ${ }^{3}$ Department of

Pathology, Affiliated Hospital of

Academy of Military Medical Sciences,

Beijing, ${ }^{4}$ Department of Pathology,

Chinese People's Armed Police Force,

Zhejiang Corps Hospital, Jiaxing,

Zhejiang, People's Republic of China

*These authors contributed equally to this work
This article was published in the following Dove Press journal:

OncoTargets and Therapy

15 July 2016

Number of times this article has been viewed

\begin{abstract}
ROS1 rearrangement has recently emerged as a new molecular subtype in non-small cell lung cancer, and is predominantly found in lung adenocarcinomas compared with other oncogenes such as EGFR, KRAS, or $A L K$. Patients who have both mutations are extremely rare. Here we report a 50-year-old female diagnosed with adenocarcinoma with sarcomatoid differentiation, who was shown to have EGFR and ROS1 mutations. The patient was treated surgically and received three cycles of adjuvant postoperative chemotherapy. In addition, we reviewed the previously reported cases and related literature. This presentation will provide further understanding of the underlying molecular biology and optimal treatment for non-small cell lung cancer patients with more than one driver mutation.
\end{abstract}

Keywords: non-small cell lung cancer, EGFR gene mutation, ROS1 fusion gene

\section{Introduction}

Non-small cell lung cancer (NSCLC) is still the leading cause of cancer-related deaths worldwide. The prognosis is poor for most patients with NSCLC, even with the most current treatment regimens, which include surgery, chemotherapy, and radiation. Targeted molecular therapy is effective for advanced NSCLC patients with associated gene mutations. Although driver genes, including epidermal growth factor receptor $(E G F R)$ and Kirsten rat sarcoma viral oncogene (KRAS), are common molecules in lung adenocarcinomas, the c-ros oncogene 1 receptor tyrosine kinase (ROS1) rearrangement has been identified in only $1 \%-2 \%$ of NSCLC cases. ${ }^{1,2}$ Previous studies have suggested that ROS1 fusion is exclusive to EGFR, KRAS, or $A L K$ mutations and presents in a greater percentage of tumors that lack other genetic changes associated with lung cancer. ${ }^{3-5}$ Nevertheless, at least four patients with an EGFR mutation and ROSI fusion have been reported thus far in the world literature. ${ }^{6}$ The patient reported herein is the fifth case, and also the first case with an EGFR exon 21 L858R point mutation and CD74-ROS1 fusion gene. Little is known about the prognostic value, clinical presentation, predictive value for different therapy regimens, and the genetic heterogeneity for two gene-positive NSCLC patients. All protocols in the present study were approved by the Human Clinical and Research Ethics Committees of the Zhejiang Corps Hospital (Jiaxing, People's Republic of China). The patient provided written informed consent.

\section{Case report}

A 50-year-old female who had never smoked was evaluated for persistent cough and shown by computed tomography (CT) scanning to have a $32 \mathrm{~mm}$ tumor in the right lower 


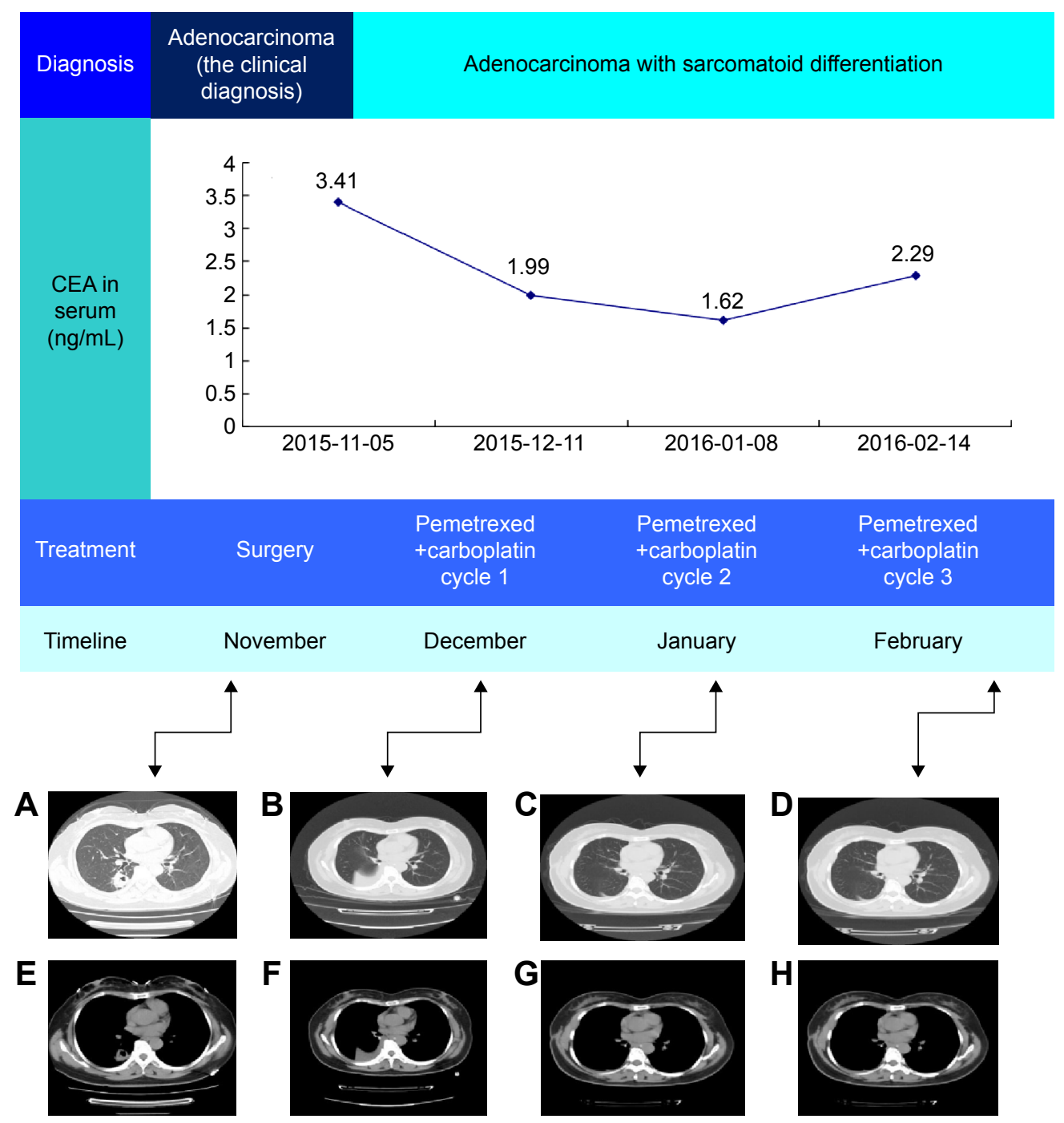

Figure I Treatment of lung adenocarcinoma with sarcomatoid differentiation using different chemotherapy regimens and results of monitoring the CEA levels.

Notes: (A-D) Lung CT scans from (A) November 2015, (B) December 2015, (C) January 2016, and (D) February 2016. (E-H) CT scans of the mediastinum from (E) November 2015, (F) December 2015, (G) January 2016, and (H) February 2016.

Abbreviations: CEA, carcinoembryonic antigen; CT, computed tomography.

lobe of the lung in November 2015 (Figure 1). No significant medical history was reported and no abnormalities were found on physical examination. Imaging examinations, including abdominal $\mathrm{CT}$, brain magnetic resonance imaging, and bone emission computed tomography, were normal and blood laboratory testing was within normal limits, including a biochemistry and coagulation profile, and routine hematologic parameters.

The patient underwent resection of the right lower lobe and en bloc resection of the associated hilar and mediastinal lymph nodes by video-assisted thoracic surgery. The postoperative course was uneventful and the patient recovered quickly. The postoperative pathology showed that the tumor was an adenocarcinoma with sarcomatoid differentiation (Figure 2). Immunochemistry staining was positive for the following markers: vimentin; thyroid nuclear factor 1; P63; cytokeratin 7; and cytokeratin 5/6 (Table 1 and Figure 2). The tumor was stage $\mathrm{Ib}\left(\mathrm{T}_{2 \mathrm{a}} \mathrm{N}_{0} \mathrm{M}_{0}\right)$. Gene detection for mutations was performed on a formalin-fixed, paraffin-embedded tibia tumor specimen by next-generation sequencing and fusion genes, and $c$-Met 14 skipping mutation by polymerase chain reaction or fluorescence in situ hybridization on portions of the adenocarcinoma and sarcomatoid differentiation, respectively. A variant of the ROS1 translocation (Table 2 and Figure 3) and the EGFR exon 21 L858R point mutation were detected (Table 3 and Figure 3). The patient received three cycles of postoperative adjuvant chemotherapy. No recurrence of the tumor was noted by CT scanning during 3 months of follow-up care (Figure 1). The CEA level ranged from a pretreatment level of $3.41 \mathrm{ng} / \mathrm{mL}$ to a postoperative level of $2.29 \mathrm{ng} / \mathrm{mL}$ (Figure 1). 

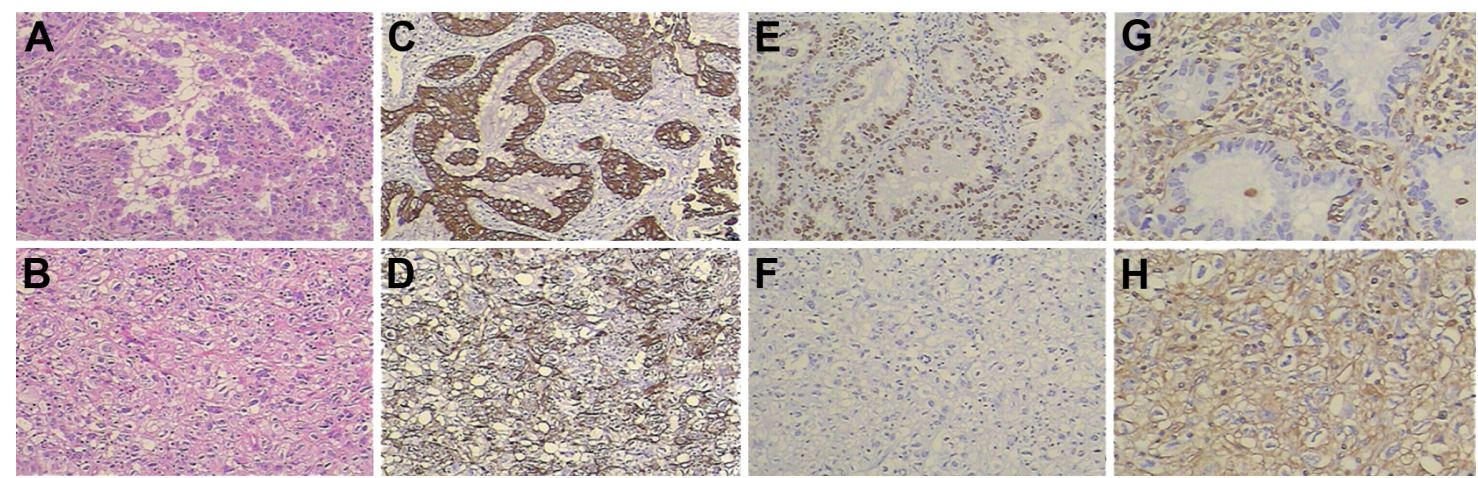

Figure 2 The hematoxylin-eosin staining and the immunohistochemistry in the part of adenocarcinoma and sarcomatoid differentiation.

Notes: (A) The hematoxylin-eosin staining revealed that tumor cells were lung adenocarcinoma $(\times 100)$. (B) The hematoxylin-eosin staining revealed that tumor cells were sarcomatoid differentiation $(\times 100)$. (C) Immunohistochemical examination revealed that tumor cells were positive for monoclonal anti-CK7 antibody in a portion of the adenocarcinoma $(\times 100)$. (D) Immunohistochemical examination revealed that tumor cells were positive for monoclonal anti-CK7 antibody in a portion of the sarcomatoid differentiation $(\times 100)$. (E) Immunohistochemical examination revealed that tumor cells were positive for monoclonal anti-TTF-I antibody in a portion of the adenocarcinoma $(\times 100)$. (F) Immunohistochemical examination revealed that tumor cells were positive for monoclonal anti-TTF-I antibody in a portion of sarcomatoid differentiation $(\times 100)$. (G) Immunohistochemical examination revealed that tumor cells were positive for monoclonal antivimentin antibody in a portion of adenocarcinoma $(\times 100)$. (H) Immunohistochemical examination revealed that tumor cells were positive for monoclonal antivimentin antibody in a portion of sarcomatoid differentiation $(\times 100)$.

\section{Discussion}

The EGFR gene, which is located on the $12-14$ region of short arm of chromosome 7, consists of 28 exons, and most mutations are located within exons 19-21 of the tyrosine kinase domain. ${ }^{7-9}$ Point mutations in exon 21 and overlapping deletions in exon 19 account for $\sim 85 \%$ of all mutations. ${ }^{10,11}$

The ROS1 rearrangement in NSCLC was discovered by Rikova et al. ${ }^{12}$ The fusion partners include CD74-, SLC34A2-, SDC4-, EZR-, FIG-, TPM3-, LRIG3-, and KDELR2-. CD74- is the most common fusion partner in NSCLC. ${ }^{3}$ ROS1 (chromosome 6q22) encodes a receptor tyrosine kinase that belongs to the insulin receptor family and stimulates downstream signaling via the mitogen-activated protein kinases pathway, resulting in enhanced cell growth, proliferation, and decreased apoptosis. The frequency of ROS1 rearrangements ranges from $0.9 \%$ to $1.7 \%$ in an unselected NSCLC population. ${ }^{1,13,14}$ However, the frequency increases from $3.9 \%$ to $7.4 \%$ in lung adenocarcinoma patients with wild-type $E G F R / K R A S / A L K .4,5$

The EGFR tyrosine kinase inhibitors (TKIs), such as erlotinib, gefitinib, and icotinib, have been widely used as first-line treatment and have higher sensitivity compared to platinum-based chemotherapy in advanced NSCLC patients

Table I Primary antibodies used for immunohistochemical staining

\begin{tabular}{llll}
\hline Antibody & Clone & Dilution & Purchased from \\
\hline Vimentin & EP2I & $\mathrm{I}: 100$ & Zymed Laboratories, Inc. \\
TTF-I & SPT24 & $\mathrm{I}: 100$ & Zymed Laboratories, Inc. \\
P63 & UMAB4 & $\mathrm{I}: 100$ & Zymed Laboratories, Inc. \\
CK7 & EPI6 & $\mathrm{I}: 100$ & Zymed Laboratories, Inc. \\
CK5/6 & D5/16B4 & $\mathrm{I}: 100$ & Zymed Laboratories, Inc. \\
\hline
\end{tabular}

Notes: Zymed Laboratories, Inc. (South San Francisco, CA, USA).

Abbreviations: CK, cytokeratin; TTF-I, thyroid nuclear factor I. with EGFR mutations. ${ }^{15-17}$ Deletions in exon 19 and L858R point mutations in exon 21 are the most sensitive mutations with a clear benefit from EGFR TKI treatment.

ROS1-positive patients do not benefit from treatment with EGFR TKIs. ${ }^{4,5}$ In contrast, patients appear to benefit from treatment with crizotinib, an orally bioavailable anaplastic lymphoma kinase (ALK) inhibitor. ${ }^{18,19}$ Crizotinib is currently undergoing Phase III clinical trials globally. It is anticipated that ROS1-positive NSCLC behaves in an analogous manner to EGFR mutant NSCLC, and crizotinib could represent an advance in NSCLC treatment.

Patients who have a ROS1 gene fusion and EGFR mutation are extremely rare. Previous studies have suggested

Table 2 Gene mutation identified by next-generation sequencing of the patient

\begin{tabular}{ll}
\hline Gene & Type \\
\hline EGFR mut & L858R \\
KRAS mut & Wild type \\
BRAF mut & Wild type \\
PIK3CA mut & Wild type \\
NRAS mut & Wild type \\
KIT mut & Wild type \\
PDGFRA mut & Wild type \\
ERBB2 mut & Wild type \\
DDR2 mut & Wild type \\
ALK mut & Wild type \\
RET mut & Wild type \\
FLT3 mut & Wild type \\
DNMT3A mut & Wild type \\
NPMI mut & Wild type \\
ABLI mut & Wild type \\
SMO mut & Wild type \\
TSCI mut & Wild type \\
\hline
\end{tabular}

Abbreviation: mut, mutation. 


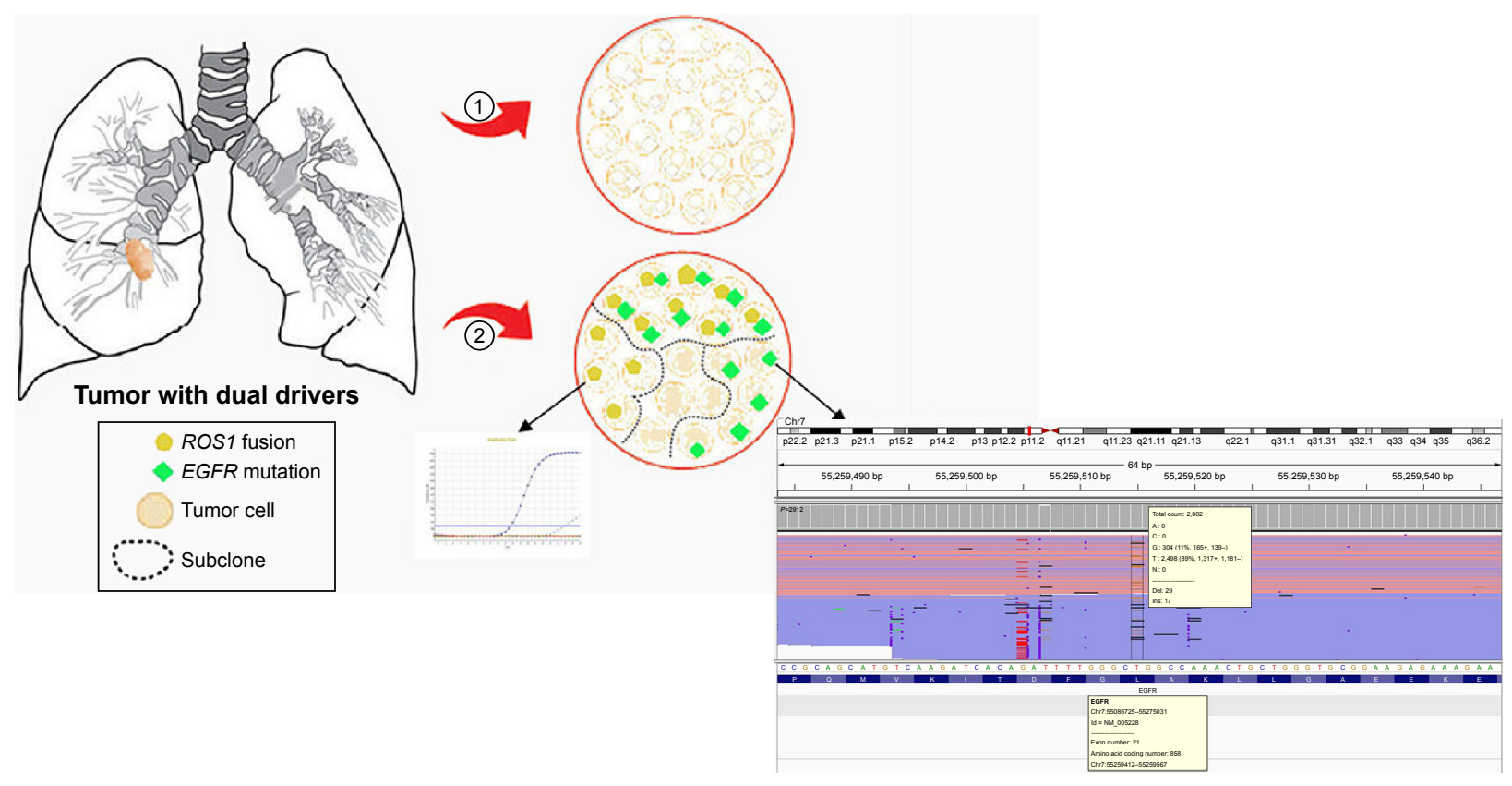

Figure 3 Schema shows tumor with dual drivers (CD74-ROSI fusion gene by polymerase chain reaction and EGFR exon 2 I L858R point mutation by next-generation sequencing) in a portion of the adenocarcinoma (I), and tumor with no driver or unknown driver in a portion of the sarcomatoid differentiation (2).

that an EGFR mutation and ROS1 gene fusion are mutually exclusive molecular events. We reviewed the literature for both EGFR and ROS1 mutations in NSCLC and found only five cases, including the present case, ${ }^{6}$ as shown in Table 4. Indeed, this is the first case in the Han Chinese population identified with a concurrent EGFR exon 21 L858R point mutation and a ROS1 fusion gene with a fusion partner (CD74-). Table 4 shows the clinical features of patients with the concomitant genes presented in our study include never-smokers $(5 / 5)$, adenocarcinoma (4/5), and adenocarcinoma with sarcomatoid differentiation (1/5), exon 19 (3/5), 20 insertion (1/5), and an exon 21 (1/5) mutation of EGFR. Two patients with advanced NSCLC harboring concomitant ROS1 rearrangements and an EGFR exon 19 deletion achieved a partial response after first-line gefitinib treatment. The patient presented herein underwent surgery and received three cycles of postoperative adjuvant chemotherapy based on pathology stage $\mathrm{Ib}$ and uncleared results

Table 3 Noteworthy results identified by PCR or FISH of the patient

\begin{tabular}{ll}
\hline Gene & Type \\
\hline ALK fusion & Negative \\
ROSI fusion & CD74-ROSI \\
RET fusion & Negative \\
NTRKI fusion & Negative \\
c-Met amp & Negative \\
c-Met I 4 skipping mut & Negative \\
\hline
\end{tabular}

Abbreviations: FISH, fluorescence in situ hybridization; PCR, polymerase chain reaction; mut, mutation. of postoperative adjuvant TKI therapy, according to the National Comprehensive Cancer Network clinical practice guidelines.

\section{Limitations}

Our study had some limitations. First, one case of a primary lung tumor included a dominance of adenocarcinoma cells with sarcomatoid differentiation, so we do not know whether or not both mutations were related to tumor tissue heterogeneity. Second, the response to TKIs in this patient is unknown because TKIs were not used.

\section{Conclusion}

We report a rare case of lung cancer in a patient harboring both an EGFR mutation and a ROS1 fusion gene. The surgery and postoperative adjuvant chemotherapy showed a good response. For patients with this subtype, further research and experience are needed to summarize the biologic features and optimal modes of treatment, including targeted therapy in advanced lung cancer patients.

\section{Acknowledgments}

This work was supported by the Science and Technology Planning Project of Zhejiang Province, People's Republic of China (grant no 2015C33194), Young Talent Innovation Project in Fujian Province, People's Republic of China (2014J05085) and Youth Innovation Research Foundation of Health department of Fujian Province of China (2014-1-15). The authors 
Table 4 Clinical features of five patients with the ROSI fusion gene and EGFR mutation

\begin{tabular}{|c|c|c|c|c|c|}
\hline Patient no & I & 2 & 3 & 4 & 5 (present case) \\
\hline Ethnicity & Chinese & Chinese & Chinese & Chinese & Chinese \\
\hline Age (years old) & NA & $\mathrm{NA}$ & NA & NA & 50 \\
\hline Sex & NA & $\mathrm{NA}$ & NA & NA & Female \\
\hline Smoking history & Never smoker & Never smoker & Never smoker & Never smoker & Never smoker \\
\hline Histology & Adenocarcinoma & Adenocarcinoma & Adenocarcinoma & Adenocarcinoma & $\begin{array}{l}\text { Adenocarcinoma with } \\
\text { sarcomatoid differentiation }\end{array}$ \\
\hline Primary lesion & NA & NA & NA & NA & The right inferior lung lobe \\
\hline TNM staging & NA & NA & NA & NA & $\mathrm{T}_{2 \mathrm{a}} \mathrm{N}_{0} \mathrm{M}_{0}$ stage $\mathrm{lb}$ \\
\hline EGFR mutation status & 19del & 19del & 19del & 20-ins & L858R \\
\hline ROSI fusion partner & NA & NA & NA & NA & CD74 \\
\hline First-line treatment & Gefitinib & Gefitinib & NA & NA & Surgery \\
\hline $\begin{array}{l}\text { First-line treatment } \\
\text { assessment }\end{array}$ & Partial response & Partial response & NA & NA & $\mathrm{R}_{0}$ resection $^{\mathrm{a}}$ \\
\hline
\end{tabular}

Note: aComplete resection with no microscopic residual tumor.

Abbreviation: NA, not available.

are very grateful to Dr David Cushley, International Science Editing, for assistance with editing the manuscript.

\section{Disclosure}

The authors report no conflicts of interest in this work.

\section{References}

1. Bergethon K, Shaw AT, Ou SH, et al. ROS1 rearrangements define a unique molecular class of lung cancers. J Clin Oncol. 2012;30(8):863-870.

2. Davies KD, Le AT, Theodoro MF, et al. Identifying and targeting ROS1 gene fusions in non-small cell lung cancer. Clin Cancer Res. 2012; 18(17):4570-4579.

3. Kim HR, Lim SM, Kim HJ, et al. The frequency and impact of ROS1 rearrangement on clinical outcomes in never smokers with lung adenocarcinoma. Ann Oncol. 2013;24(9):2364-2370.

4. Wu S, Wang J, Zhou L, et al. Clinicopathological characteristics and outcomes of ROS1-rearranged patients with lung adenocarcinoma without EGFR, KRAS mutations and ALK rearrangements. Thorac Cancer. 2015;6(4):413-420.

5. Mescam-Mancini L, Lantuéjoul S, Moro-Sibilot D, et al. On the relevance of a testing algorithm for the detection of ROS1-rearranged lung adenocarcinomas. Lung Cancer. 2014;83(2):168-173.

6. Chen R, Yang J, Zhang X, et al. ROS1 rearrangement coexists with EGFR mutation in non-small-cell lung cancer. J Clin Oncol. 2015; 33(Suppl):[abstr e19003].

7. Kosaka T, Yatabe Y, Endoh H, Kuwano H, Takahashi T, Mitsudomi T. Mutations of the epidermal growth factor receptor gene in lung cancer: biological and clinical implications. Cancer Res. 2004;64(24): 8919-8923.

8. Li Y, Li Y, Yang T, et al. Clinical significance of EML4-ALK fusion gene and association with EGFR and KRAS gene mutations in 208 Chinese patients with non-small cell lung cancer. PLoS One. 2013;8(1):e52093.
9. Shigematsu H, Lin L, Takahashi T, et al. Clinical and biological features associated with epidermal growth factor receptor gene mutations in lung cancers. J Natl Cancer Inst. 2005;97(5):339-346.

10. Lynch TJ, Bell DW, Sordella R, et al. Activating mutations in the epidermal growth factor receptor underlying responsiveness of non-small-cell lung cancer to gefitinib. $N$ Engl J Med. 2004;350(21):2129-2139.

11. Paez JG, Jänne PA, Lee JC, et al. EGFR mutations in lung cancer: correlation with clinical response to gefitinib therapy. Science. 2004; 304(5676):1497-1500.

12. Rikova K, Guo A, Zeng Q, et al. Global survey of phosphotyrosine signaling identifies oncogenic kinases in lung cancer. Cell. 2007; 131(6):1190-1203.

13. Takeuchi K, Soda M, Togashi Y, et al. RET, ROS1 and ALK fusions in lung cancer. Nat Med. 2012;18(3):378-381.

14. Rimkunas VM, Crosby KE, Li D, et al. Analysis of receptor tyrosine kinase ROS1-positive tumors in non-small cell lung cancer: identification of a FIG-ROS1 fusion. Clin Cancer Res. 2012;18(16):4449-4457.

15. Maemondo M, Inoue A, Kobayashi K, et al. Gefitinib or chemotherapy for non-small-cell lung cancer with mutated EGFR. NEngl J Med. 2010; 362(25):2380-2388.

16. Sequist LV, Yang JC, Yamamoto N, et al. Phase III study of afatinib or cisplatin plus pemetrexed in patients with metastatic lung adenocarcinoma with EGFR mutations. J Clin Oncol. 2013;31(27):3327-3334.

17. Wu YL, Zhou C, $\mathrm{Hu} \mathrm{CP}$, et al. Afatinib versus cisplatin plus gemcitabine for first-line treatment of Asian patients with advanced non-small-cell lung cancer harbouring EGFR mutations (LUX-Lung 6): an open-label, randomised phase 3 trial. Lancet Oncol. 2014;15(2):213-222.

18. Mazières J, Zalcman G, Crinò L, et al. Crizotinib therapy for advanced lung adenocarcinoma and a ROS1 rearrangement: results from the EUROS1 cohort. J Clin Oncol. 2015;33(9):992-999.

19. Shaw AT, Ou SH, Bang YJ, et al. Crizotinib in ROS1-rearranged nonsmall-cell lung cancer. N Engl J Med. 2014;371(21):1963-1971.
OncoTargets and Therapy

\section{Publish your work in this journal}

OncoTargets and Therapy is an international, peer-reviewed, open access journal focusing on the pathological basis of all cancers, potential targets for therapy and treatment protocols employed to improve the management of cancer patients. The journal also focuses on the impact of management programs and new therapeutic agents and protocols on

\section{Dovepress}

patient perspectives such as quality of life, adherence and satisfaction. The manuscript management system is completely online and includes a very quick and fair peer-review system, which is all easy to use. Visit http://www.dovepress.com/testimonials.php to read real quotes from published authors. 